\title{
Intravascular Hemolysis after Transcatheter Closure of a Huge Tubular Patent Ductus Arteriosus Using Cera-duct Occluder: Managed Successfully by Conservative Treatment
}

\author{
Sarker MFR ${ }^{1}$, Begum NNF², Ferdous $\mathrm{J}^{3}$, Bhuiyan $\mathrm{N}^{14}$, Khan MAA ${ }^{5}$, Ahmad $^{6}{ }^{6}$ \\ DOI:https://doi.org/10.3329/jafmc.v16i2.55309
}

\begin{abstract}
Isolated patent ductus arteriosus (PDA) is seen in approximately 1 in 2000 full-term life birth neonate. Transcatheter device closure is widely considered as the treatment of choice for the patient diagnosed with PDA considering the safety, efficacy and less invasiveness. Residual flow following transcatheter device closure of PDA can result in haemolysis. Our patient was a case of 9.5 years old female child weighing1 $\mathrm{kg}$ diagnosed as a case of large tubular PDA with severe pulmonary hypertension by echocardiography. The patient had history of recurrent chest infection, breathlessness on exertion, and growth failure. The PDA was closed by transcatheter approach using Cera-duct occluder. The patient subsequently developed hemolysis which started $18 \mathrm{hrs}$ after the intervention and the resolution of hemolysis achieved by conservative management within 72 hours.
\end{abstract}

Key-words: Patent ductus arteriosus, Transcatheter device closure, Haematuria.

\section{Introduction}

Patent ductus arteriosus (PDA) is a common acyanotic congenital heart disease with an incidence of $5-10 \%$ of all congenital heart defects ${ }^{1,2}$. PDA might lead to volume overload, pneumonia, heart failure depending on the shunt volume or size of the duct and if remain untreated irreversible complications such as Eisenmenger syndrome may develop $p^{3,4,5}$. Transcatheter closure using implantable devices is now the main approach for treating many congenital heart diseases including PDA which is safe, effective, and less invasive. The first successful transcatheter PDA closure was described by Porstmann in $1967^{6}$. However, transcatheter closure approach might cause complications like injury to vessels, device embolization, narrowing of adjacent vessels and hemolysis due to residual leak, as a result of mechanical exposure of the devices to blood flow ${ }^{7}$. Residual flow might happen after PDA closure with transcatheter approach which is the most important cause of hemolysis. Hemolysis is most commonly seen if PDA closed with thrombogenic coil with residual shunt and unlikely if closure of the PDA done by transcatheter approach using device or coil having no residual shunt ${ }^{8,9}$.

\section{Case Report}

A 9.5 years old female child was admitted for evaluation of dyspnoea on exertion, palpitation, not gaining weight since birth. On admission physical examination showed pectus carinatum deformity of the chest, intercostal recession, shifting of apexbeat to left 5th intercostal space (ICS) lateral to the midclavicular line, heaving apex beat, loud $\mathrm{P} 2$ with continuous machinery murmur on auscultation.

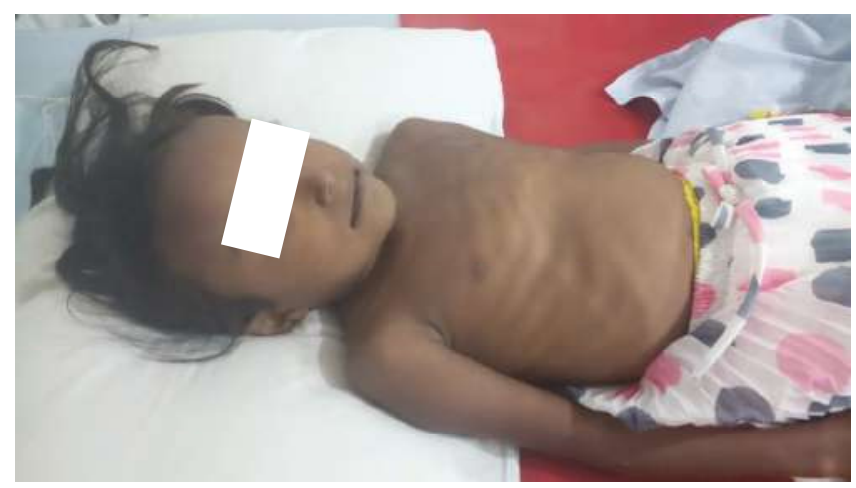

Figure-1: Pectus carinatum deformity of chest with sign of respiratory distress.

Chest X-ray showed huge cardiomegaly with plethoric lung field. The ECG showed left atrial (LA) and ventricular hypertrophy (LVH). Color Doppler Echocardiography showed, huge tubular PDA (Pulmonary end $7.8 \mathrm{~mm}$, aortic end $11 \mathrm{~mm}$ ) with left to right shunt. LA, LV, main pulmonary artery (MPA), and branch PAs are dilated with severe pulmonary hypertension, calculated pulmonary artery systolic pressure (CPASP) recorded $60 \mathrm{~mm} \mathrm{Hg}$.

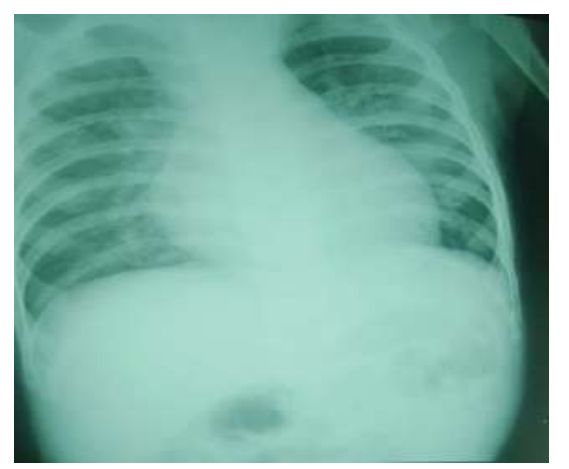

Figure-1: X-ray chest P/A view shows cardiomegaly with plethoric lung field.

1. Col Md Ferdousur Rahman Sarker, MBBS, FCPS, DCH, Paediatric Cardiac Interventionist, CMH, Dhaka (E-mail: ferdous868@yahoo.com) 2. Brig Gen Nurun Nahar Fatema Begum, SBP, MBBS, FCPS, FRCP, FACC, FSCAl, Congenital and Structural Cardiac Interventionist, Adviser Specialist \& Head, Department of Paediatrics \& Paediatric Cardiology, CMH, Dhaka 3. Lt Col Jannatul Ferdous, MBBS, FCPS, MCPS, Paediatric Interventional Cardiologist, CMH, Dhaka 4. Lt Col Nazmul Islam Bhuiyan, MBBS, FCPS, Paediatric Interventional Cardiologist, CMH, Dhaka 5. Lt Col Md Ashfaque Ahemmed Khan, MBBS, DCH, FCPS, Paediatric Interventional Cardiologist, CMH, Dhaka 6. Col Mushtaq Ahmad, MBBS, MCPS, DFM, Professor \& Head, Department of Forensic Medicine, AFMC, Dhaka. 


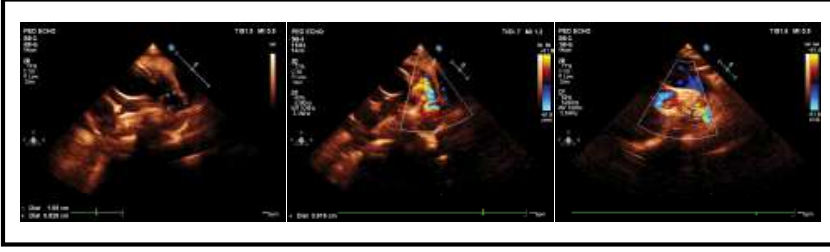

Figure-3: Echocardiography shows huge tubular PDA.

The patient was scheduled for cardiac catheterization and PDA device closure. A $5 \mathrm{Fr}$ BBA catheter introduced into MPA through right femoral venous approach and the pulmonary pressure was recorded $90 / 35(54) \mathrm{mm}$ of $\mathrm{Hg}$. Flush aortogram with right femoral arterial approach showed huge tubular PDA. Aortic pressure recorded 100/28 (52) $\mathrm{mm} \mathrm{Hg}$. Fluoroscopically pulmonary end was $08 \mathrm{~mm}$, aortic end $10.5 \mathrm{~mm}$. The ratio of pulmonary to systemic flow (QP: QS) was calculated 2.5:1. The patient was decided for PDA device closure with 14x12 mm Cera PDA device. A 5Fr MPA catheter was introduced through the right Femoral vein into RV and PA then PDA crossed with the help of a 0.035 Terumo guide wire. A 0.035 super stiff exchange wire was introduced through the MPA catheter and catheter removed. Inj Heparin $100 \mathrm{IU} / \mathrm{Kg}$ was given intravenously before the exchange wire placed in descending aorta (DAO).

A 7Fr delivery sheath introduced up to DAO over the guide wire and guide wire removed. A 14x12 mm Cera device loaded with a loader and introduced through the delivery sheath and deployed in PDA. After device deployment hand injection with a $5 \mathrm{fr}$ BBA catheter in DAO showed a tiny residual leak through the side of the device. The patient was stable throughout the procedure. After device deployment, PA pressure recorded 40/25 (30) $\mathrm{mm} \mathrm{Hg}$ and aortic pressure $110 / 70$ (82) $\mathrm{mm} \mathrm{Hg}$ which showed a significant rise of systemic diastolic pressure and a significant decrease of PA pressure. The device was then released with the hope that the residual shunt would be closed by emphraxis. As we have seen in our experience that tiny residual shunt usually close in subsequent follow up. Proper haemostasis was achieved at the puncture site.

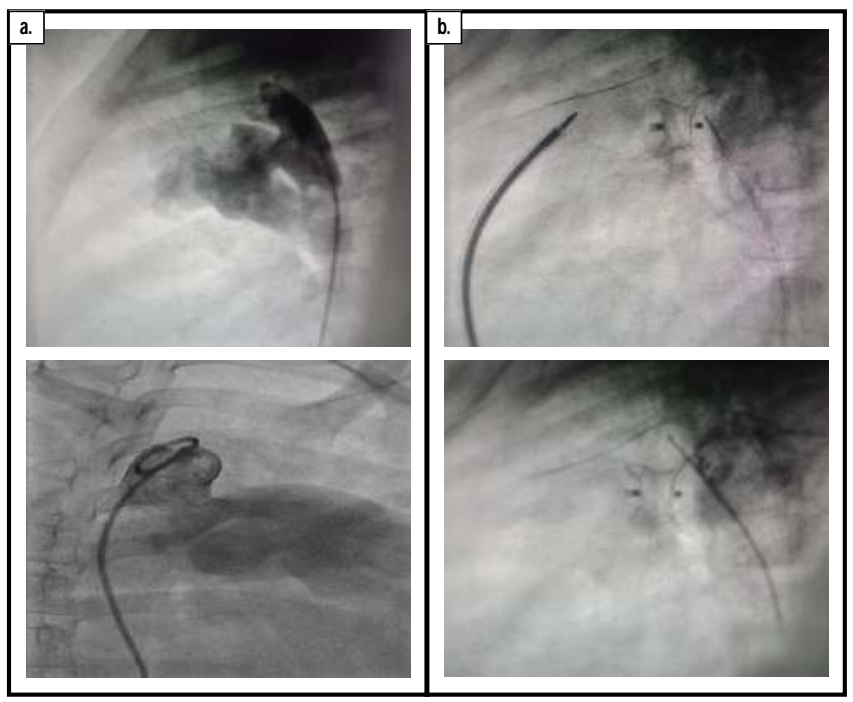

Figure-4- a: Aortogram shows large PDA b. PDA device deployment and release.
Echocardiography was done immediately after the procedure showed the device in proper position with a tiny shunt through the side of the device with laminar flow seen in descending aorta and branch PAs. The patient then shifted to Paediatric cardiac ICU. Reddish urine was first observed $18 \mathrm{hrs}$ after the procedure. Clinically patient was stable with no sign of respiratory distress with normal blood pressure. Urinalysis showed hemoglobinuria. CBC showed $\mathrm{Hb}$ level become $11.5 \mathrm{gm} / \mathrm{dl}$ from baseline $\mathrm{Hb} 12.6 \mathrm{gm} / \mathrm{dl}$. Normal S. Bilirubin, BUN, S Creatinine, ABG, and S. Electrolytes. We manage the patient with a conservative approach. Patient was kept NPO because patient may require any urgent intervention at any point of time.

Intravenous fluid started with $10 \%$ Dextrose in Baby Saline $(0.45 \% \mathrm{NaCl}) @$ dose of 1 and $1 / 2$ times of maintenance for 48 hrs to prevent renal damage and wash out damaged red blood cells. 2 units fresh frozen plasma was transfused and Injection vitamin K1 $2 m g$ intravenously given for 3 days to enhance the normal coagulation cascade. 2 days after the intervention haemolysis disappeared as evident by the color of the urine which was gradually became normal straw color. Oral fluid started and normal maintenance fluid continued for the next $24 \mathrm{hrs}$. After $72 \mathrm{hrs}$ review, echo showed negligible residual shunt. Clinically the patient was stable with normal respiratory rate and laboratory parameters. The patient was discharged on 7th post-procedure day with a review echo which showed the device in position and a trickle of flow seen through the side of the device. The patient was advised to come for follow up after 01 month.

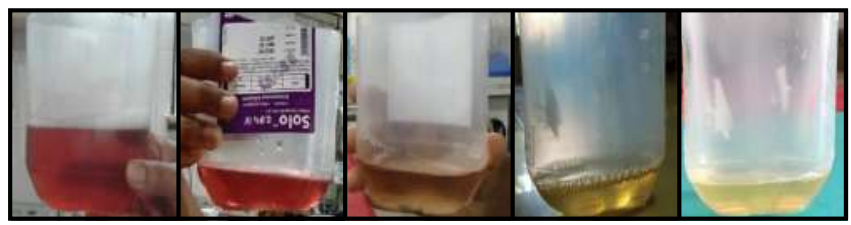

Figure-5: Transition of urine colour from dark red to normal straw colour

\section{Dscussion}

Intravascular hemolysis after transcatheter PDA device closure is a very rare complication but may be an seriously threatening condition. Haemolysis after percutaneous closure of PDA with device /coil is associated with the presence of residual ductal flow $^{10}$. The likely mechanism of hemolysis is high velocity turbulent blood flow past the ductal device, leading to mechanical fragmentation of erythrocytes ${ }^{11}$. The magnitude of the hemolysis may depend on the degree of arctation, the velocity of the shunt flow, platelet function, and the activity of fibrinolysis factors ${ }^{12}$. Hemolysis usually develops in the first 24 hours post procedure but may occur weeks later. When severe it may result in anemia, jaundice, renal failure, and coagulopathy. The usual approach to the patient with significant intravascular hemolysis is stabilization, Protection against renal damage by adequate fluid management and correction of acidosis and the elimination of residual flows by deploying thrombogenic coil ${ }^{13}$. Close monitoring of the patient with $\mathrm{CBC}$, serum electrolysis, 
BUN, S. creatinine, LFT, ABG and to take necessary corrective measure in time if possible elimination of residual shunt by deploying coils is paramount in the management of this complication following transcatheter device/coil occlusion of PDA. Intravascular hemolysis is a well-known though uncommon complication of transcatheter closure of PDA and has been reported after duct occlusion using the Raskind occluder ${ }^{14,15}$. Another study showed haemolysis following partial closure of the duct using thrombogenic coil16-18. Haemolysis also observed after closure of the duct by Amplatzer duct occluder $^{19,20}$. In this case, hemolysis disappeared with a conservative approach, the residual leak also reduced significantly without second intervention.

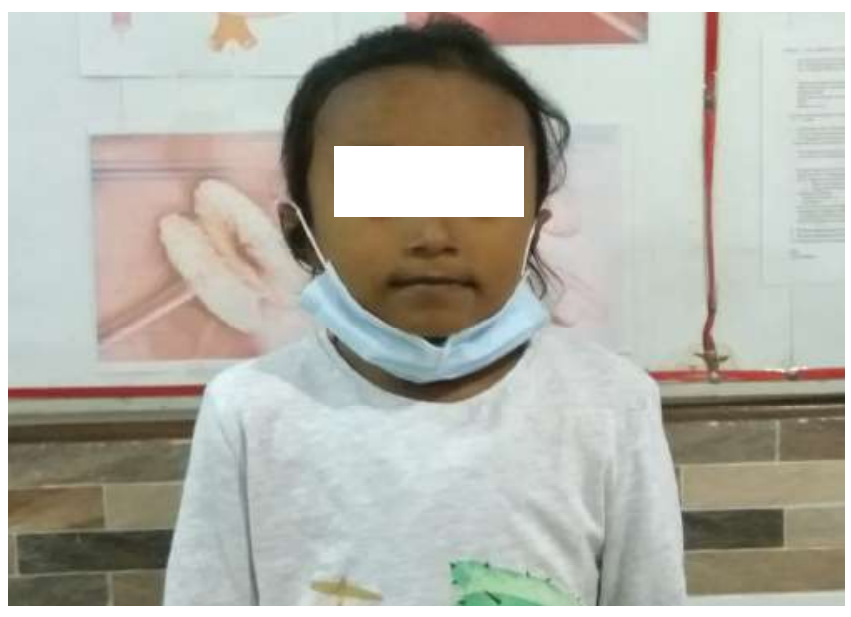

Figure-6: Happy baby at the time of discharge.

\section{Conclusion}

Transcatheter closure of PDA now-a-days the method of choice considering the safety, effectiveness and patient compliance. The incidence of intravascular hemolysis after transcatheter PDA closure is rare ranging from $0.3-0.05 \%$ of all procedures of transcatheter closure which can be managed successfully by stabilization of acute condition by a conservative approach to prevent renal damage and elimination of residual shunt by intra device deployment of coils. Close monitoring with conservative management may also cause resolution of hemolysis without any further percutaneous intervention in mild to moderate cases and this case is one of the unique examples where resolution of haemolysis achieved with conservative management.

\section{References}

1. Schneider DJ, Moore JW. Patent ductus arteriosus. Circulation. 2006; 114:1873-82.

2. Feltes TF, Bacha E, Beekman $\mathrm{RH}$ et al. Indications for cardiac catheterization and Intervention in Paediatric cardiac disease: A scientific statement from the American Heart Association. Circulation. 2011; 123:2607-52.

3. Bilkis AA, Alwi M, Hasri S et al. The Amplatzer duct occluder. Experience in 209 patients. J Am Coll Cardiol. 2001; 37:258-61.
4. Stark RJ, Shekerdemian LS. Estimating intracardiac and extracardiac shunting in the setting of complex congenital heart disease. Annals Pedcardiol. 2013; 6(2):145-51.

5. Amoozgar $H$, Salehi S, Farhoudi $P$ et al. Follow-up results of device occlusion of patent ductusarteriosus. Iran J Pediatr. 2016; 26(3):e3621.

6. Wierny L, Plass R, Porstmann W. Transluminalclosure of patent ductusarteriosus: Long- term results of 208 cases treated without thoracotomy. Cardiovase Intervent Radiol. 1986; 9:279-85

7. Long Gy, Son CS, lee JW et al. Complications aftertranscatheter closure of patent ductusarteriosus. Med Sci. 2007; 22(3):484-90.

8. Jung JW. Recent strategies and outcome of transcatheterclosure for patent ductusarteriosus. Kor Circ J. 2010; 40(5):216-8.

9. Brunett MA, Ringel $\mathrm{R}$, Owada $\mathrm{C}$ et al. Percutaneous closure of patent ductusarteriosus: A multiinstitutional registry comparing multiple devices. Catheter Cardiovasc Interv. 2010; 76(5):696-702.

10. Gupta SC, Suryaprasad AG. Mechanial hemolytic anemia after repair of ruptured chordate tendineae of mitral valve apparatus. Angiology. 1979; 30(11):776-9.

11. Moisey CU, Manohitharajah SM, Tovey LA et al. Hemolytic anemia in a child in associated with congenital mitral valve disease. J Thorac Cardiovasc Surg. 1972; 63:765-8.

12. Shim D, Wechsler Ds, Lioyd TR et al. Haemolysis following coil-occlusion of patent ductusarteriosus. Cathet Cardiovasc Diagn. 1996; 39:287-90.

13. Kapoor A, Radhakrishnan S, Shrivastava S. Severe intravascular haemolysis following coil occlusion of patent ductusarteriosus. Indian Heart J. 1996; 48:173-4.

14. Khan MAA, Yousef SA, Mullins CE et al. Experience with 205 procedures of transcatheter closure of ductus arteriosus in 182 patients, with special reference to residual shunts and long-term follow-up. J Thorac Cardiovasc Surg. 1992; 104(6):1721-7.

15. Qureshi SA, Huggon IC. Hemolysis associated with umbrella occlusion of the arterial duct. Pediatr Cardi. 1995; 16:101-2.

16. Shim D, Wechsler DS, Lloyd TR et al. Hemolysis following coil embolization of a patent ductus arteriosus. Cathet Cardiovasc Diagn. 1996; 39:287-90.

17. Henry G, Danilowicz D, Verma R. Severe hemolysis following partial coil-occlusion of patent ductus arteriosus. Cathet Cardio-vasc Diagn. 1996; 39:410-2.

18. Tomita $\mathrm{H}$, Fuse $\mathrm{S}$, Akagi $\mathrm{T}$ et al. Hemolysis complicating coil occlusion of patent ductus arteriosus. Cathet Cardiovasc Diagn. 1998; 43:50-3.

19. Godart F, Rodes J, Rey C. Severe haemolys is after transcatheter closure of a patent arterial duct with the new Amplatzer ductoccluder. Cardiol Young. 2000; 10:265-7.

20. Faella HJ, Hijazi ZM. Closure of the patent ductus arteriosus with the Amplatzer PDA device: Immediate results of the international clinical trial. Cathet Cardiovasc Intervent. 2000; 51:50-4. 